\title{
Novel blocked functionality copolymers as surface coatings in DNA microarray technology
}

\author{
M. Viganò, ${ }^{1}$ M. Levi, ${ }^{1}$ M. Chiari, ${ }^{2}$ F. Damin, ${ }^{2}$ S. Turri ${ }^{1 *}$ \\ $1^{1 *}$ Dipartimento di Chimica, Materiali e Ingegneria Chimica "Giulio Natta", Politecnico \\ di Milano, Piazza Leonardo da Vinci 32, 20133 Milan, Italy. email: \\ stefano.turri@polimi.it \\ ${ }^{2}$ Istituto di Chimica del Riconoscimento Molecolare, CNR, Via Bianco, 20100 Milan, \\ Italy.
}

(Received: 8 June, 2007; published: 8 September, 2007)

\begin{abstract}
New copolymers made of 2-(dimethyl amino) ethyl methacrylate (DMAEM) and isocyanate ethyl methacrylate blocked with methyl ethyl ketoxime (IEMB) was synthesized in various composition ratios in order to obtain water reducible copolymers after acidification. They were characterized by infrared spectroscopy, chemical titration for the determination of amine equivalent weight, and by differential scanning calorimetry (DSC). Calorimetric analysis showed the presence of a former broad endothermal peak followed by a latter, stronger exothermal one, which can be respectively attributed to the deblocking of isocyanate groups and to their subsequent reactions. Some copolymer compositions were dip coated onto microscope glass slides and surfaces were characterized by static and dynamic contact angles, revealing a clear effect of the salifying agent and a likely surface rearrangement of polar groups while in contact with water. Finally, oligonucleotides surface immobilization and molecular recognition capability of the coated glass slides were positively assessed by hybridization tests with fluorescently labelled complementary probes.
\end{abstract}

\section{Introduction}

Microarrays are small solid devices (usually of the size of a microscope glass slide or smaller) with flat surface on which hundreds or even thousands of different probe sites are deposited. Each probe allows the immobilization and recognition of one specific biomacromolecule (targets), like oligonucleotides or proteins. The feature of a highly simultaneous analysis procedure joined with the capability of working with small volumes and reduced times has made microarray technology an important tool in genomics for fast and accurate gene expression analysis [1-3] and genotyping [4, 5]. Different methods can be used for the fabrication of DNA microarray: in-situ synthesis by photolithographic techniques [6-11], and mechanical deposition by inkjet printing, spotting or spit-pin technology [6, 7, 12-16]. A large number of parameters can be used in order to define the DNA microarray quality, such as spot and probe density, background noise and spot morphology, durability, and ease of processing [6]. All these parameters are largely influenced by the chosen DNA immobilization chemistry.

The main functional group used in the microarray technology for surface functionalization are epoxides, amines and aldehydes. However in many cases microarrays obtained with these functional groups show limited storage stability, 
affecting the reproducibility of results and so requiring other chemical steps to regenerate reactive groups $[17,18]$.

Among the various chemical functionalities available, blocked isocyanates [24-26], well known and used in many surface coating applications, can be used for improving the storage stability of the microarray. In fact highly reactive NCO groups can be masked and protected by a specific group to be thermally removed just before use. This functionality, grafted onto a glass slide surface through a simple silanization procedure, was used by us [22] in a precedent work with very good results. Actually the model microarray achieved showed high binding and hybridization efficiency [22], and therefore surface treatments with blocked isocyanates show a great potential as candidate for the preparation of high performance DNA microarray. The silanization chemistry, which is the classical approach followed to attach covalently oligonucleotides to the surface [23, 24], is very flexible, rather cheap and advantageous. However, a strict control of operative conditions is needed to achieve a homogeneous monolayer or few layers deposition and, although covalent immobilization density varies in the range $10^{11}-10^{13}$ molecules $/ \mathrm{cm}^{-2}$ [7], only $40-$ $50 \%$ of the surface-bond probe is usually hybridized with the target [23]. In order to increase oligonucleotide density and fluorescent signals and therefore to amplify the sensitivity of detection, dendrimeric structures and polymer functional coatings can be used [25-27]. The molecular features of these structures reduce the steric hindrance during covalent immobilization and hybridization due to the higher distance between the functional groups [28].

Polymeric coatings can be obtained using different techniques, such as spin coating, solution casting, and dip coating. To minimize the use of organic solvents one possible solution is to develop polymers in form of aqueous dispersion. Copolymers with special functional groups such as amino, carboxylic or sulfonic are synthesized in solvent but they can be solubilised in water after acidification or basification, and are generally classified as "water reducible" [29].

The aim of this work is the preparation and testing of new blocked functionality coatings to be used in microarray technology. A series of new copolymers from 2isocyanatoethyl methacrylate (IEM) blocked with methyl ethyl ketoxime (MEKO), and 2-(dimethyl amino) ethyl methacrylate (DMAEM) were synthesized and characterized. Some of these copolymers were dispersed in water and applied onto glass slides in order to obtain the functional surface. This approach was followed for the fabrication of some model DNA microarrays by spotting technology, and their effective performances were evaluated through hybridization test.

\section{Results and discussion}

Although isocyanate groups are very reactive with many active functions present in biomacromolecules like DNA and proteins $\left(-\mathrm{NH}_{2},-\mathrm{OH}\right.$, and $\left.-\mathrm{SH}\right)$, they were so far scarcely used for biomacromolecules immobilization [30]. One possible explanation is their excessive moisture sensitivity, which could involve a loose of functionality of the NCO functionalized surface. As normally done in coating and adhesive technology [19-21], the moisture sensitivity can be minimized introducing a thermoreversible blocking agent which masks the NCO functional group. In a precedent work of us [22] it was demonstrated that MEKO blocked isocyanates can be used as functional groups for the fabrication of DNA microarray by silanization. 
In the present paper the blocked isocyanate function was incorporated in a water dispersible copolymer structure in order to further improve the quality and performance of the resulting microarray.<smiles>C=C(C)C(=O)CCCCC#CCCOC(=O)C(=C)C</smiles>

(b)

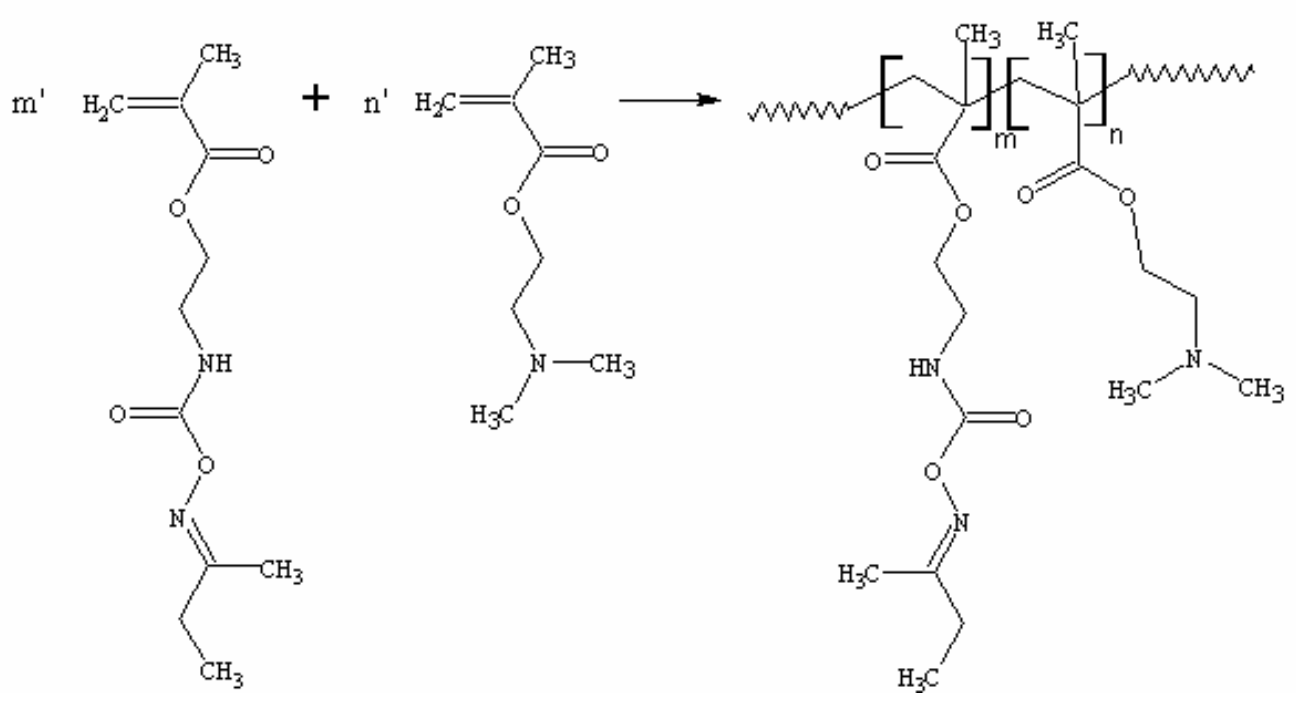

Fig. 1. (a) Blocking reaction of IEM with MEKO. (b) Copolymerization of DMAEM and IEMB; $\mathrm{m} / \mathrm{n}=0$ to $\infty$.

Tab. 1. Monomer feed and copolymer composition, yield and amino equivalent weight (EW) of the copolymers indicated as ID50, ID70 and ID90, and for the homopolymers PolyIEMB and PolyDMAEM.

\begin{tabular}{ccccc}
\hline $\begin{array}{c}\text { Copolymer } \\
\text { type }\end{array}$ & $\begin{array}{c}\text { Monomer feed } \\
\text { composition }^{\text {a) }}[\%]\end{array}$ & $\begin{array}{c}\text { Copolymer } \\
\text { composition } \\
\text { [\%] }\end{array}$ & $\begin{array}{c}\text { Yield } \\
{[\%]}\end{array}$ & $\begin{array}{c}\text { Amino equivalent } \\
\text { weight (EW) } \\
{[\mathrm{g} / \mathrm{eq} \text { ) }}\end{array}$ \\
\hline PolylEMB & 100 & - & 56.5 & - \\
ID90 & 90 & 91 & 86.9 & $2607 \pm 130$ \\
ID70 & 70 & 72 & 77.1 & $780 \pm 40$ \\
ID50 & 50 & 52 & 85.2 & $420 \pm 25$ \\
PolyDMAEM & 0 & - & 64.7 & $158 \pm 10$ \\
\hline
\end{tabular}

\footnotetext{
a) $\mathrm{mol}_{\text {IEMB }} / \mathrm{mol}_{\text {DMAEM+IEMB }}$
}

b) Calculated via titration

Several copolymers with different compositions were synthesized by free radical polymerization and characterized before using it for the glass slides functionalization through dip coating. Different monomer feeds as high as 50, 70 and $90 \%$ (expressed as mol IEMB $/ \mathrm{mol}_{\text {DMAEM+IEMB }}$ ) were copolymerized. They are indicated as ID50, ID70 and ID90. The homopolymer of IEMB (polyIEMB) and DMAEM (polyDMAEM) were also prepared in the same way. Fig. 1-b reports the general copolymerization scheme and 
the results of characterization are shown in Table 1. Composition was determined both by ${ }^{1} \mathrm{H}-\mathrm{NMR}$ spectroscopy and chemical titration of tertiary amine side groups. Signals at $3.52 \mathrm{ppm}$ (assigned to $-\mathrm{CH}_{2} \mathrm{NH}$ - in IEMB monomer) and at $4.07 \mathrm{ppm}$ ($\mathrm{CH}_{2} \mathrm{O}$ - groups in both monomers) can be integrated and used to determine the copolymer composition, and the results are in good agreement with those obtained from the chemical titration. Only copolymers with IEMB content higher than $50 \%$ molar were however considered in the following application tests in order to obtain functionalized surface with a high density of NCO functional groups.

The thermal behaviour of the new copolymers was investigated by DSC. Figure 2 shows as an example the whole DSC cycle carried out for ID70 product. The DSC traces for all the other copolymers and for PolylEMB are qualitatively similar, and calorimetric data are summarized in Table 2. In the first heating run from -50 to +280 ${ }^{\circ} \mathrm{C}$ the $\mathrm{T}_{\mathrm{g}}$ of ID70 can be observed at $+28^{\circ} \mathrm{C}$, followed at first by a broad endothermal peak probably due to the deblocking reaction and evaporation of the blocking agent, and then at higher temperature by a much stronger exothermal peak.

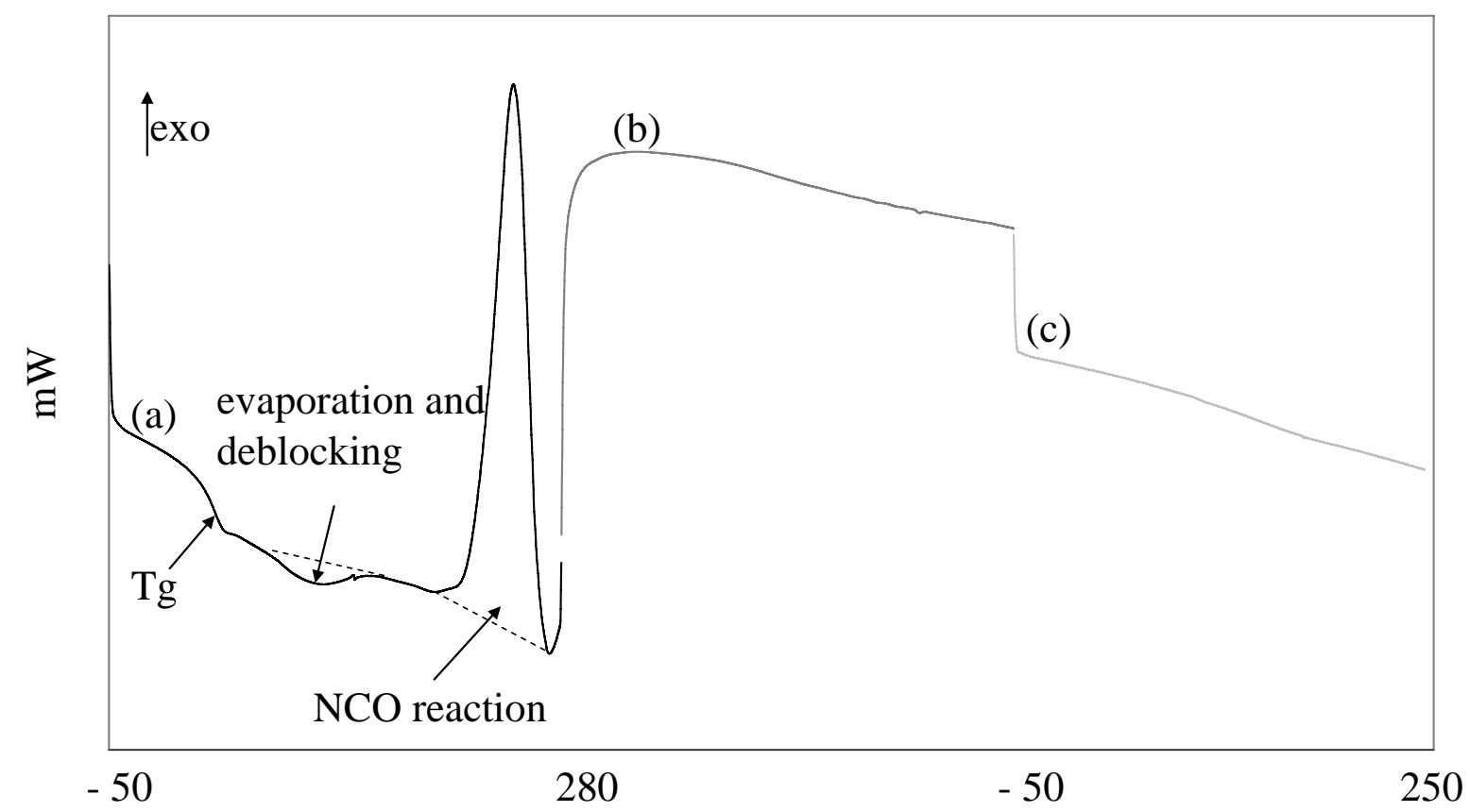

Temperature $\left[{ }^{\circ} \mathrm{C}\right]$

Fig. 2. Complete DSC cycle for ID70: (a) first heating run from -50 to $-280{ }^{\circ} \mathrm{C}$, (b) cooling run from 280 to $-50^{\circ} \mathrm{C}$ and (c) second heating run from -50 to $250^{\circ} \mathrm{C}$.

As shown in Table 2 the exothermal enthalpy peak $\Delta \mathrm{H}$ increases proportionally to IEMB weight fraction in the copolymer (Figure 3 ). It is therefore supposed that the exothermal peak is due to reaction of deblocked NCO groups, for example to their possible cyclotrimerization or other addition reactions. Moreover, the exothermal peak temperature decreases proportionally to the DMAEM weight fraction in the copolymer. This effect may due to the catalytic effect of tertiary amino groups on NCO reactions [29]. The second and third runs are flat, without clear evidence of peak or heat capacity changes. It suggests that during the first run a complete 
deblocking occurs followed by reaction of all free isocyanate groups, crosslinking and likely $\mathrm{T}_{\mathrm{g}}$ shift to higher temperature.

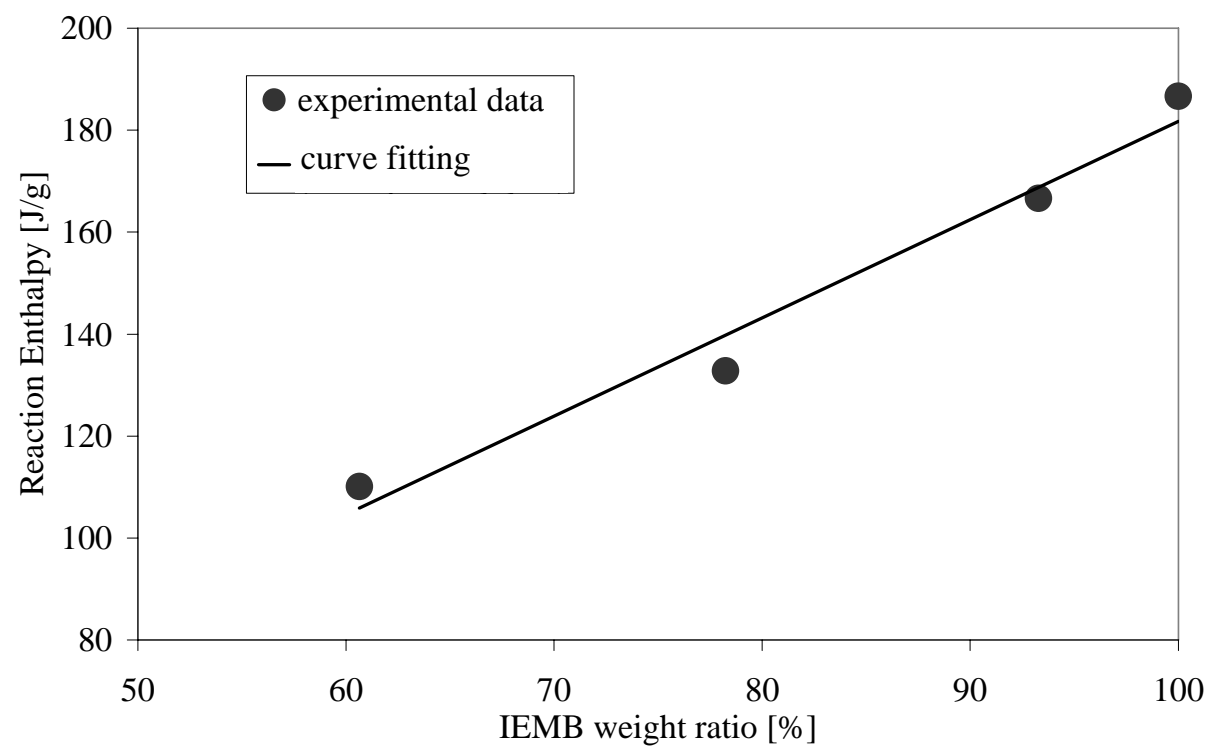

Fig. 3. Enthalpy change of NCO group reactions as a function of IEMB weight ratio.

In the case of PolyDMAEM the DSC traces appear quite different (data not shown). In the first heating run, $\mathrm{T}_{\mathrm{g}}$ can be observed the at $+20^{\circ} \mathrm{C}$, followed by a small broad endothermal peak, probably due to the evaporation of a residual part of solvent entrapped in the polymer. In the second and third run only the $\mathrm{T}_{\mathrm{g}}$ at +26 and $+32{ }^{\circ} \mathrm{C}$ respectively can be observed. The difference between $\mathrm{T}_{\mathrm{g}}$ in the first and third run can be due to the evaporation of the residual solvent which acts as a plasticizer of the polymer.

Tab. 2. IEMB weight ratio, $\mathrm{Tg}$ and crosslinking a) DSC data for of the copolymers ID50, ID70 and ID90, and for the homopolymers PolyIEMB and PolyDMAEM.

\begin{tabular}{ccccc}
\hline Polymer & $\begin{array}{c}\text { Weight ratio of } \\
\text { IEMB [\%] }\end{array}$ & $\mathrm{Tg}$ & \multicolumn{2}{c}{ Crosslinking ${ }^{\text {a) }}$} \\
\cline { 4 - 5 } & 100 & 32.5 & Peak temperature $\left[{ }^{\circ} \mathrm{C}\right]$ & $\Delta \mathrm{H}[\mathrm{J} / \mathrm{g}]$ \\
\hline PolylEMB & 93 & 25.1 & 249.4 & 186.66 \\
ID90 & 78 & 28.0 & 247.8 & 166.63 \\
ID70 & 61 & 26.9 & 245.6 & 132.80 \\
ID50 & 0 & 20.22 & 243.2 & 110.12 \\
PolyDMAEM & 0 & - & - \\
\hline
\end{tabular}

a) With "crosslinking" all the possible reactions involving free isocyanates are indicated.

Surfaces dip coated in 0.1 and $1 \% \mathrm{w} / \mathrm{w}$ ID50 and ID70 aqueous solutions were then characterized and compared. Copolymers were salified with $\mathrm{HCl}$ or acetic acid before dissolving them in water. The coated glass slides were dried and tested through static (SCA) and dynamic (DCA) contact angle measurements against water and diiodomethane, and hybridization functional tests with amino terminated oligonucleotides.

In the following part the coated surfaces were briefly called IDXX-S-YY\%, where IDXX indicates the type of copolymer used (ID50 or ID70), and YY is the 
concentration of the dip solution. If not differently specified the copolymers were acidified with hydrochloric acid. Results of contact angle and surface tension measurements are shown in Table 3. Dispersive surface tension $\left(\gamma_{s}{ }^{d}\right)$ values showed negligible differences in the behaviour of the two polymeric systems. On the other hand polar surface tension $\left(\gamma_{s}^{p}\right)$ showed a more significant difference in the behaviour of the two coatings acidified with hydrochloric acid: the difference is about $-20 \mathrm{mN} / \mathrm{m}$ passing from ID50 to ID70 with both the solution concentration considered. This effect is likely due to the higher molar ratio of the salified DMAEM ammonium group in ID50 respect to ID70.

Tab. 3. Static contact angles, total surface tension and its components of isocyanate-silane treated glass slides.

\begin{tabular}{|c|c|c|c|c|c|}
\hline \multirow{2}{*}{$\begin{array}{l}\text { Coated } \\
\text { surfaces }\end{array}$} & \multicolumn{2}{|c|}{ Static contact angle $\pm \mathrm{SD}^{\text {a) }}$} & \multirow{2}{*}{$\begin{array}{c}\mathrm{Ys}_{\mathrm{s}} \\
{[\mathrm{mN} / \mathrm{m}]}\end{array}$} & \multirow{2}{*}{$\begin{array}{c}\mathrm{Ys}^{\mathrm{d}} \\
{[\mathrm{mN} / \mathrm{m}]}\end{array}$} & \multirow{2}{*}{$\begin{array}{c}\mathrm{Vss}^{\mathrm{p}} \\
{[\mathrm{mN} / \mathrm{m}]}\end{array}$} \\
\hline & water & diiodomethane & & & \\
\hline ID50-S-0.1\% & $57.24 \pm 21.69$ & $47.61 \pm 2.73$ & 48.26 & 28.30 & 19.96 \\
\hline ID50-S-1\% & $34.85 \pm 4.50$ & $42.54 \pm 1.12$ & 61.11 & 23.77 & 37.34 \\
\hline $\begin{array}{l}\text { ID50-S-0.1\% } \\
\mathrm{CH}_{3} \mathrm{COOH}\end{array}$ & $70.20 \pm 3.03$ & $49.33 \pm 3.41$ & 40.93 & 29.26 & 11.67 \\
\hline $\begin{array}{l}\text { ID50-S-1\% } \\
\mathrm{CH}_{3} \mathrm{COOH}\end{array}$ & $68.27 \pm 1.48$ & $40.94 \pm 1.48$ & 44.76 & 33.60 & 11.16 \\
\hline ID70-S-0.1\% & $94.19 \pm 5.11$ & $50.84 \pm 7.85$ & 33.27 & 31.71 & 1.57 \\
\hline ID70-S-1\% & $59.98 \pm 18.4$ & $38.75 \pm 1.84$ & 47.48 & 30.10 & 17.37 \\
\hline
\end{tabular}

a) Errors are shown with standard deviation (SD).

b) $\gamma_{s}$ is the surface free energy, $\gamma_{s}{ }^{d}$ is its dispersive component and $\gamma_{s}{ }^{p}$ polar component and errors are shown with standard error (SE).

Similar effect was observed passing from 0.1 to $1 \%$ solution concentration for both the polymeric systems. The behaviour could be due to the increasing amount of the quaternary ammonium salts, which in the presence of water could orient themselves towards the surface increasing its overall polar character. On the other hand no solution concentration effect was observed in the systems acidified with acetic acid. Comparing the ID50 based systems with the two different acids (Table 3), it can be observed that those treated with acetic acid show lower $\gamma_{s}{ }^{p}$. Acetic acid is less strong than $\mathrm{HCl}$, and the corresponding ammonium salt is therefore less hydrophilic. The influence of the acid on the surface behaviour of the coated glass slides can be observed also in the dynamic cycle (Figure 4). The plots of the DCA as function of the time for ID50-S-1\% (Figure 4-A) and ID50-S-1\% $\mathrm{CH}_{3} \mathrm{COOH}$ (Figure 4-B) appear very different. In the case of ID50-S-1\% the advancing contact angles decrease quickly, with a decrement of $33^{\circ}$ after 15 cycles. On the other hand for ID50-S-1\% $\mathrm{CH}_{3} \mathrm{COOH}$ the decrement after 15 cycles is $23^{\circ}$. The difference between the first and the last advancing contact angle, also indicated as kinetic hysteresis, may be indicative of the superficial rearrangement of some functional groups, which in the present case could be the migration of the quaternary ammonium salts from the bulk to the surface. The lower kinetic hysteresis for ID50-S-1\% $\mathrm{CH}_{3} \mathrm{COOH}$ is probably due to the acid strength lower for acetic acid than $\mathrm{HCl}$. Interestingly enough no significant difference can be observed in the kinetic hysteresis of ID50-S-0.1\% and ID50-S-0.1\% $\mathrm{CH}_{3} \mathrm{COOH}$ systems, for which the difference between the first and the last advancing contact angle is about $12^{\circ}$. Evidently the nature of ionic group is less important for 
the thinner layer, where they are likely more adherent to the glass surface. In all cases, solubilisation of polymer components during measurements could be excluded because the surface tension of the test liquids (water and diiodomethane) remained unchanged.
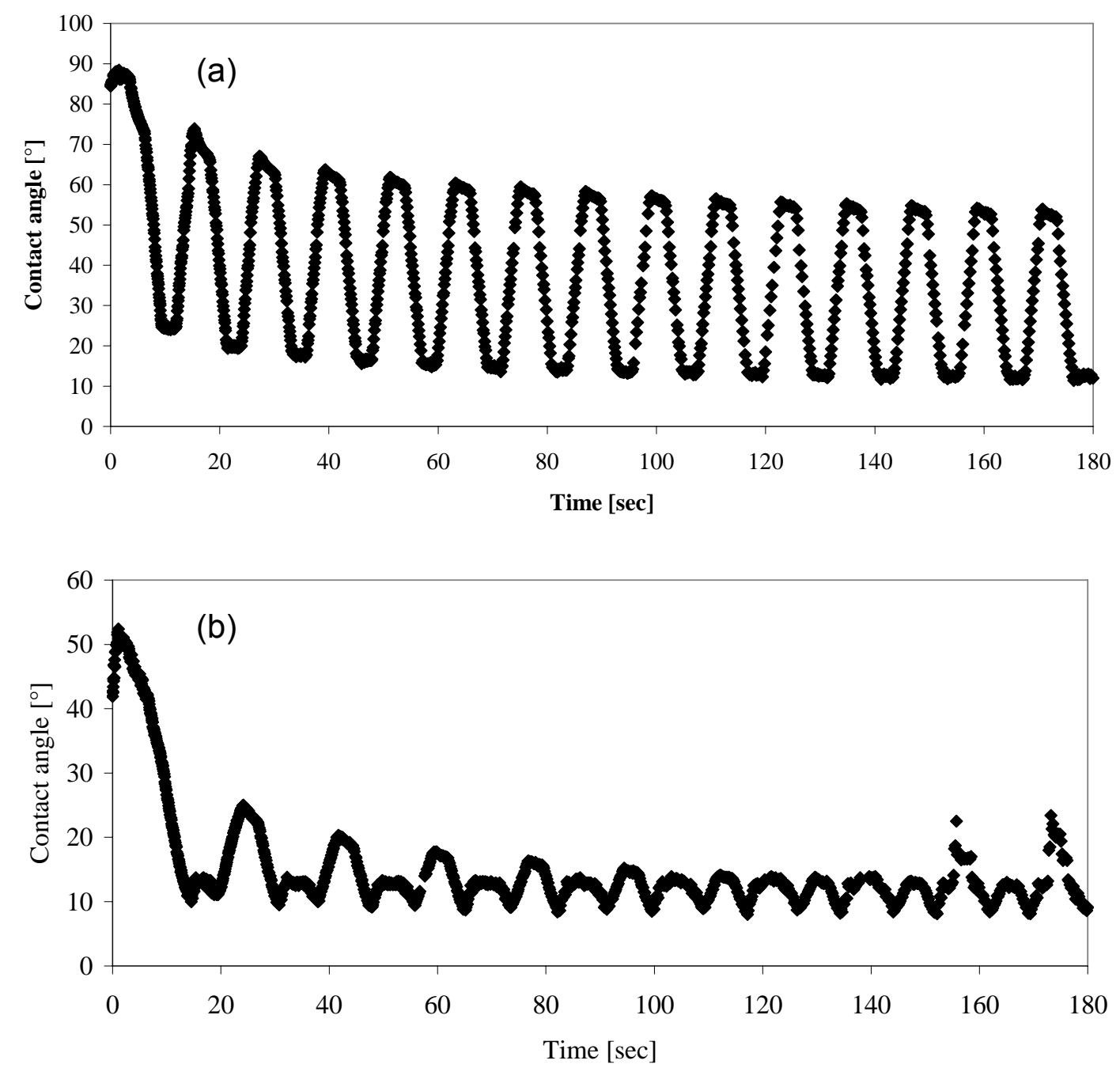

Fig. 4. Dynamic water contact angle measurements for (a) ID50-S-1\% and (b) ID50$\mathrm{S}-1 \% \mathrm{CH}_{3} \mathrm{COOH}$

The analysis of the receding contact angle and the consequent measurement of the molar free energy of hysteresis $\Delta G_{h}[31]$ is feasible only in case of surfaces coated with the polymer salified with acetic acid, since when $\mathrm{HCl}$ is used for both ID50 and ID70 coatings the receding angle is too low to be accurately measured. Actually for these systems the receding contact angle reported from the instrument (Figure 4-B) is not the true value but rather a measurement of the angle which water forms between needle and surface.

In the case of the surface coated with the polymer salified with acetic acid an effect of the solution concentration on $\Delta G_{h}$ value can be observed. The $\Delta G_{h}$ increase from 1867 to $2831 \mathrm{~J} / \mathrm{mol}$ passing from 0.1 to $1 \%$ solution concentration. This behavior could be due to the formation of a more homogeneous surface at high dilution, with hydrophilic ammonium salts more ordered towards the glass-polymer interface. 
To assess the suitability of the new coatings in microarray technology, the behaviour of the coated glass slides for DNA immobilization was investigated through hybridization test. An amino terminated non-fluorescent oligonucleotide was spotted on the surface and its hybridization capability has been tested by coupling with the fluorescent labelled complementary target. Glass treated substrates were previously thermally activated as explained in the experimental part, in order to remove the blocking agent. The variables explored were the content of $\mathrm{NCO}$ groups in the copolymer (50 and $70 \%$ molar), the aqueous polymer solution concentration ( 0.1 and $1 \%$ ), and the acid type (hydrochloric or acetic).

Quantitative results in terms of fluorescence intensities, signal-to-noise ratio, and spot diameters are summarized in Table 4, while Figure 5 shows as an example the fluorescence microscopy images for (a) ID50-S-1\%, (b) ID70-S-1\% and (c) ID50-S$1 \% \mathrm{CH}_{3} \mathrm{COOH}$ coated surfaces. It also gives qualitative information about the shape, regularity and the diameter of the spots, which are highly valuable parameters of a high quality microarray.

Tab. 4. Mean value of fluorescence intensity and standard deviation (SD), signal-tonoise ratio and spot diameter for ID50-S-0.1\%, ID50-S-1\%, ID50-S-0.1\% $\mathrm{CH}_{3} \mathrm{COOH}$, ID50-S-1\% $\mathrm{CH}_{3} \mathrm{COOH}$, ID70-S-0.1\%, ID70-S-1\%.

\begin{tabular}{|c|c|c|c|}
\hline Sample & $\begin{array}{c}\text { Fluorescence } \\
\text { intensity }[A F U] \\
\text { Mean } \pm S D^{a)}\end{array}$ & $\begin{array}{l}\text { Signal-to-noise } \\
\text { ratio Mean } \pm \text { SD }\end{array}$ & $\begin{array}{l}\text { Spot diameter }[\mu \mathrm{m}]]^{\mathrm{b})} \\
\text { Mean } \pm S D^{\text {a) }}\end{array}$ \\
\hline ID50-S-0.1\% & $8229 \pm 2569$ & $209 \pm 104$ & $117 \pm 35$ \\
\hline ID50-S-1\% & $11731 \pm 5495$ & $36 \pm 32$ & $120 \pm 28$ \\
\hline $\begin{array}{l}\text { ID50-S-0.1\% } \\
\mathrm{CH}_{3} \mathrm{COOH}\end{array}$ & $5841 \pm 4705$ & $124 \pm 93$ & $108 \pm 13$ \\
\hline ID50-S-1\% $\mathrm{CH}_{3} \mathrm{COOH}$ & $12044 \pm 4616$ & $15 \pm 11$ & $117 \pm 25$ \\
\hline ID70-S-0.1\% & $4886 \pm 3344$ & $125 \pm 75$ & $108 \pm 11$ \\
\hline ID70-S-1\% & $18129 \pm 3991$ & $43 \pm 16$ & $129 \pm 20$ \\
\hline
\end{tabular}

a) Errors are shown with standard deviation (SD).

b) The spot diameter was calculated measuring the diameter of the circle inscribed in the spot.

The hybridization intensities of polymer systems acidified with hydrochloric acid are higher at increasing fraction of active NCO groups. The ID50-S-1\% system shows well defined and circular spots, allowing quite accurate and quantitative evaluation of the fluorescence intensity through the scanner, which approximates the spot like a dot. On the other hand, the ID70-S-1\% system shows less regular spots with poorly defined profiles.

For those systems there is also a partial lack of adhesion of the polymeric coating during the washing procedure. This behaviour is probably due to the extensive surface reorganization when it is exposed to water as shown before by dynamic contact angle. In the case of ID50-S-1\% $\mathrm{CH}_{3} \mathrm{COOH}$, having a less intense kinetic hysteresis effect, no detachment of the polymeric layer was observed. The change of salifying agent increases the stability of the polymeric coating without worsening the DNA microarray functionality of the surface; actually comparing the fluorescence intensity, the spot diameter (Table 4), and shape (Figure 5) of this system with those of ID50-S-1\% negligible difference are observed. 

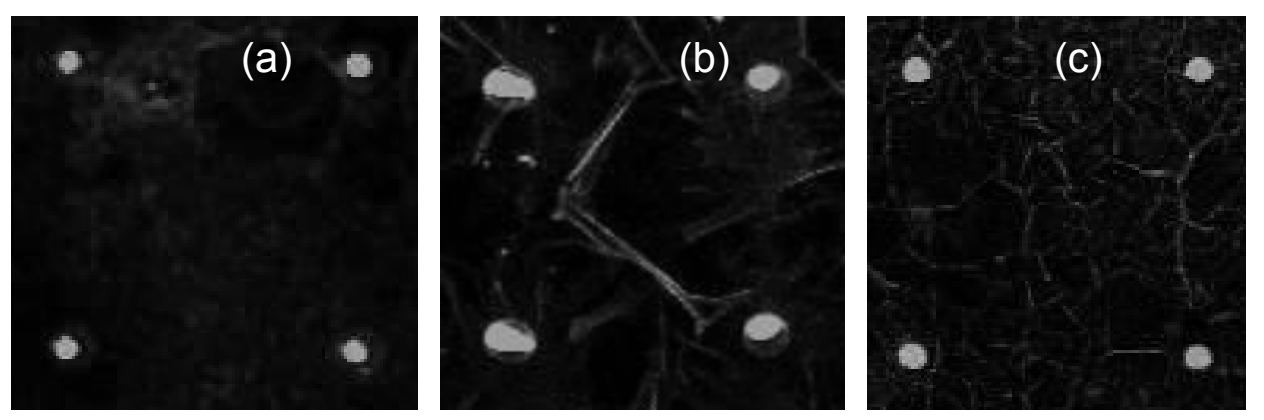

Fig. 5. Fluorescence microscopy images for (A) ID50-S-1\%, (B) ID70-S-1\% and (C) ID50-S-1\% $\mathrm{CH}_{3} \mathrm{COOH}$ coated surfaces.

Solution concentration influences the hybridization performance of the system, actually the fluorescence intensities of $0.1 \%$ systems are lower than those of $1 \%$ systems (Table 4). The signal-to-noise ratio for all the arrays applied at $1 \%$ is quite low, and this does not allow the obtainment of a good optical contrast of the deposition zones. On the other hand, although the fluorescence intensity signals are low, the signal-to-noise ratio for the $0.1 \%$ applied systems are more intense.

In conclusion, in this work new copolymers of 2-(dimethyl amino) ethyl methacrylate (DMAEM) and isocyanate ethyl methacrylate blocked with methyl ethyl ketoxime (IEMB) were synthesized in various compositive ratios. Some of these structures were dip coated onto microscope glass slides obtaining functionalized and stable surfaces which are promising candidates for the fabrication of high quality microarrays. The NCO functionality, masked by the blocking group in order to ensure prolonged shelf-life of the device, can be simply restored by heating the glass slides before use. The oligonucleotides immobilization and recognition capability of the coated glass slides were investigated by preliminary hybridization tests. Results showed, especially in the case of ID50-S- $1 \% \mathrm{CH}_{3} \mathrm{COOH}$ coating, a positive overall performance of the models prepared. This system presents a good compromise among fluorescence intensity, spot shape and adhesion with the glass support. Points to be improved are the signal-to-noise ratio, and the need to optimize both molecular weight and composition of the copolymers for a complete compatibility of the new coatings with the microarray technology.

\section{Experimental part}

\section{Materials}

Isocyanate ethyl methacrylate (IEM), 2-(dimethyl amino) ethyl methacrylate (DMAEM), hexane, methyl ethyl ketoxime (MEKO), dibutyltin dilaurate (DBTDL), $\alpha, \alpha$ 'azoisobutyronitrile (AIBN), tetrahydrofuran (THF), hydrochloric acid ( $\mathrm{HCl})$, acetic acid $\left(\mathrm{CH}_{3} \mathrm{COOH}\right)$, bromophenol blue, untreated glass microscope slides $\left(25 \times 75 \mathrm{~cm}^{2}\right)$ and the highest purity grade of diiodomethane $\left(\mathrm{CH}_{2} \mathrm{I}_{2}\right)$ were all purchased from Sigma (St. Luis, MO). THF was distilled, degassed and stored over dry molecular sieves before use.

Ethanolamine and sodium dodecyl sulphate (SDS) were supplied from Merck (Darmstadt, Germany). Oligonucleotides, 23-mer amino modified at the 5' terminus, 23-mer Cy3-oligonucleotides labelled at the 5' terminus and 23-mer Cy3-oligonucleotides amino modified at 3 ' terminus and labelled at the 5 ' terminus were purchased from MWG-Biotech AG (Ebevsberg, Germany). 
Tris[hydroxymethyl]aminomethane (Tris) was from Promega (Madison, USA). $\mathrm{NaCl}$ and sodium citrate were from Serva (Heidelberg, Germany).

\section{Blocked isocyanate monomer synthesis}

All glassware was oven dried at $120{ }^{\circ} \mathrm{C}$ overnight and reactions were carried out under purified nitrogen atmosphere. A droplet of DBTDL $(0,02 \% \mathrm{w} / \mathrm{w}$ respect to IEM) was added to isocyanate ethyl methacrylate. The mixture was degassed by alternating vacuum and nitrogen purge for a few minutes, then it was kept under magnetical stirring at $60{ }^{\circ} \mathrm{C}$. Successively, MEKO (5\% molar excess on NCO) was added dropwise. The scheme of reaction is reported in Fig. 1a. The reaction mixture was kept at $60{ }^{\circ} \mathrm{C}$ until the free isocyanate groups were blocked (checked by FTIR spectroscopy monitoring the disappearance of $-\mathrm{NCO}$ stretching band at about 2260 $\left.\mathrm{cm}^{-1}\right)$.

\section{Copolymer synthesis}

MEKO blocked isocyanate ethyl methacrylate (IEMB in the following), DMAEM and AIBN $(0,1 \% \mathrm{~mol} / \mathrm{mol}$ on IEMB + DMAEM) were dissolved in distilled dry THF $(30 \%$ $\mathrm{w} / \mathrm{w}$ solution) in a round-bottom flask equipped with condenser, magnetic stirrer and nitrogen connection. The reaction mixture was degassed by alternating vacuum and nitrogen purge for a few minutes and kept at $70{ }^{\circ} \mathrm{C}$ under nitrogen for 24 hours. Different monomer feeds as high as 50, 70 and $90 \%$ (expressed as $\mathrm{mol}_{\text {IEMB }} / \mathrm{mol}_{\mathrm{DMAEM}+\mathrm{IEMB}}$ ) were copolymerized. They are indicated as ID50, ID70 and ID90. The homopolymer of IEMB (polyIEMB) and DMAEM (polyDMAEM) were also prepared in the same way. Fig. 1-b reports the general copolymerization scheme.

The copolymers were purified by precipitation using hexane as non-solvent. They were then again dissolved in THF and reprecipitated three times in order to purify the polymers and remove the residual monomers which are soluble in toluene. The copolymers were then left in vacuum $(50 \mathrm{~mm} \mathrm{Hg})$ until constant weight was reached in order to remove the residual solvent. For PolyIEMB the same procedure was followed, but toluene instead of hexane was used as non-solvent.

\section{Polymer characterization}

The amino equivalent weight (EW) was obtained by chemical titration using the following procedure: about $0.25 \mathrm{~g}$ of copolymers were dissolved in $15 \mathrm{ml}$ THF and 5 $\mathrm{ml}$ of water under magnetic stirring. Two drops of indicator (bromophenol blue) was added to the system, and then hydrochloric acid $(0.102 \mathrm{~N})$ until the colour changed from blue to yellow. EW was obtained by the following equation:

$$
E W_{I D x x}=\frac{m_{I D x x}}{V \cdot N}
$$

where $m_{I D x x}$ is the copolymer weight dissolved in THF, $V$ is the volume of $\mathrm{HCl}$ and $N$ is the normality of $\mathrm{HCl}(0.102 \mathrm{~N})$. The real copolymer composition can be obtained from EW using the following equations:

$$
\begin{aligned}
& E W_{I D x x}=M W_{I E M B} \cdot a+M W_{D M A E M} \\
& x_{I D x x}=\frac{a}{a+1}
\end{aligned}
$$


where $a$ is the ratio between the number of IEMB molecules and those of DMAEM, $M W_{I E M B}$ and $M W_{D M A E M}$ are the molecular weight of IEMB and DMAEM respectively and $x$ is the molar ratio of IEMB.

${ }^{1} \mathrm{H}-\mathrm{NMR}$ spectra were recorded with a Bruker $300 \mathrm{MHz}$ instrument. The samples were dissolved in $\mathrm{D}_{2} \mathrm{O}$ or deuterated DMSO (chemical shifts in ppm: $0.85,1.01,1.12$, $1.80,1.97,2.25,2.59,3.52,3.52,4.07,6.73)$. The FTIR spectra of the samples were recorded using a Termo-Nicolet FTIR Nexus infrared spectrometer with a nominal resolution of $4 \mathrm{~cm}^{-1}$.

Differential scanning calorimetry (DSC) was carried out with a Mettler-Toledo DSC $823^{\mathrm{e}}$ instrument, with the following thermal cycle: first heating from $-50^{\circ} \mathrm{C}$ to $280{ }^{\circ} \mathrm{C}$, cooling from $280{ }^{\circ} \mathrm{C}$ to $-50{ }^{\circ} \mathrm{C}$ and second heating from $-50{ }^{\circ} \mathrm{C}$ to $250{ }^{\circ} \mathrm{C}$ (rate 10 $\left.{ }^{\circ} \mathrm{C} / \mathrm{min}\right)$.

\section{Glass slide coating}

Microscope glass slides $(2.5 \times 7.5 \mathrm{~cm})$ were accurately cleaned according to the following dipping procedure: ethanol for $30 \mathrm{~min}, 1 \mathrm{M} \mathrm{HCl}$ solution for another $1 \mathrm{~h}$, rinsing with distilled water, drying, $1 \mathrm{M} \mathrm{NaOH}$ solution for other $30 \mathrm{~min}$, rinsing again with distilled water and drying. The cleaned glass slides were dip-coated into a solution of the polymers for $30 \mathrm{~min}$ at room temperature. The copolymer aqueous solutions were obtained according to the following procedure: 1) the copolymers were dissolved in the least volume of THF; 2) the stoichiometric quantity of hydrochloric acid or acetic acid was added drop wise to the solution and then 3 ) the necessary amount of water was added in order to obtain solution at 1 and $0.1 \% \mathrm{w} / \mathrm{w}$. After coating, the slides were air-dried and then stored in a dry environment until use.

\section{Surface characterization}

Static and dynamic contact angles were performed with an OCA20 instrument (Dataphysics Co., Germany), equipped with a photo camera CCD and with a $500 \mu \mathrm{L}-$ Hamilton syringe to dispense liquid droplets. The same instrument was used to control the surface tension of water and diiodomethane by drop shape analysis. Static measurements were made at room temperature by means of the sessile drop technique. At least ten measurements were performed at different places on each sample and results were averaged. Bidistilled water and the highest purity grade of diiodomethane were used as probe liquids, and the delivered volume was $1.25 \mu \mathrm{L}$. Contact angle $(\theta)$ data were carried out with time interval of $1 \mathrm{~s}$ between drop deposition and the measurement. Total surface tension $\gamma_{s}$, and their dispersive $\gamma_{s}{ }^{d}$ and polar $\gamma_{s}^{p}$ components were calculated by the Young equation (eq. 4) and the OWRK (Owens, Wendt, Rabel and Kaelble) geometric mean approximation [32] reported below (eq. 5), using for water $\gamma_{I}=72.3 \mathrm{mN} / \mathrm{m}=\gamma_{1}{ }^{d}+\gamma_{1}^{p}=18.7+53.6 \mathrm{mN} / \mathrm{m}$, and for diiodomethane $\gamma_{I}=50.8 \mathrm{mN} / \mathrm{m}=\gamma_{1}{ }^{d}+\gamma_{1}{ }^{p}=49.5+1.3 \mathrm{mN} / \mathrm{m}$.

$$
\begin{aligned}
& \gamma_{l} \cos \vartheta=\gamma_{s}-\gamma_{s l} \\
& \gamma_{s l}=\gamma_{s}+\gamma_{l}-2 \sqrt{\gamma_{s}^{d} \gamma_{l}^{d}}-2 \sqrt{\gamma_{s}^{p} \gamma_{l}^{p}}
\end{aligned}
$$

Dynamic measurements were made at room temperature by means of the sessile drop (needle in) technique. Bidistilled water was used as probe liquid. The tests were carried out using a pre-drop of $0.5 \mu \mathrm{L}$. A volume of $3 \mu \mathrm{L}$ was delivered and drained away during the measurement of the advancing and receding contact angle 
respectively, and 15 cycles were made in order to measure the thermodynamic and the kinetic hysteresis. An evaluation of the thermodynamic hysteresis was obtained using Extrand equation [31]:

$$
\Delta G_{h}=-R T \ln \frac{\sin \theta_{r}}{\sin \theta_{a}}
$$

where $\theta_{a}$ and $\theta_{r}$ are the advancing and receding contact angles respectively, $R$ is the gas constant, $T$ is the Kelvin temperature and $\Delta G_{h}$ is molar free energy of hysteresis. Kinetics hysteresis was evaluated by the difference between the advancing contact angle value of the first cycle and those of the fifteenth.

\section{Microarray fabrication and functional tests}

\section{-Oligonucleotide probe immobilization}

Synthetic 23-mer 5'-amine-modified oligonucleotides (100 $\mu \mathrm{M} / \mathrm{mL}$ stock solution) were dissolved in $150 \mathrm{mM}$ sodium phosphate buffer $\mathrm{pH} 8.5$. This solution of oligonucleotides at $10 \mu \mathrm{M}$ concentration was printed onto coated glass slides to form a 400 spots microarray using a Qarray ${ }^{2}$ spotter (Genetix, UK). Spotting was carried out at $+12{ }^{\circ} \mathrm{C}$ and $33 \%$ humidity. Printed slides were placed in an uncovered storage box, laid in a sealed chamber, saturated with $\mathrm{NaCl}$, and incubated overnight. The glass supports coated with the polymers were previously deblocked and then incubated at room temperature. The deblocking reaction was carried out at $180^{\circ} \mathrm{C}$ under vacuum for $10 \mathrm{~min}$. After incubation, all residual reactive groups of the glass surface were eliminated by dipping the slides in $50 \mathrm{mM}$ ethanolamine/0.1\% SDS/0.1 M Tris pH 9.0 at $50{ }^{\circ} \mathrm{C}$ for $15 \mathrm{~min}(10 \mathrm{~mL}$ of this blocking solution for each slide). Then, the slides were washed two times with water and dipped for $15 \mathrm{~min}$ in $4 \times$ SSC $/ 0.1 \%$ SDS buffer, prewarmed at $50{ }^{\circ} \mathrm{C}$ and rinsed with water and dried.

\section{-Hybridization with complementary oligonucleotides}

Complementary 23-mer oligonucletides labelled at the $5^{\prime}$ terminus with Cy3 were dissolved in the hybridisation buffer (2x SSC/0.1\% SDS/0.02\% BSA) at a concentration of $1 \mu \mathrm{M}$ and immediately spread to microarray spotted area $\left(2.5 \mu \mathrm{L} / \mathrm{cm}^{2}\right.$ of coverslip applied on treated zone). The slides were placed in the hybridisation chamber, laid in a humidified incubator at $65^{\circ} \mathrm{C}$ for at least $2 \mathrm{~h}$. Afterwards, the slides were shaken in $4 \times$ SSC at room temperature to remove the coverslip and then they were washed twice for 5 minutes with $2 \times$ SSC/0.1\% SDS solution, prewarmed at hybridisation temperature. This operation was followed by other two washings with $0.2 \times \mathrm{SSC}$ and $0.1 \times \mathrm{SSC}$, carried out both at room temperature for 1 minute. Finally, the slides were dried using a centrifuge and so they were ready to be scanned with confocal laser scanner, ScanArray Lite (Perkin Elmer, MA, USA). Fluorescence signals were measured with the laser power kept constant at $22 \%$ and the photomultiplier tube gain at $64 \%$.

\section{References}

[1] Schena, M.; Shalon, D.; Davis, R.W.; Brown, P.O. Science 1995, 270, 467.

[2] DeRisi, J.L.; lyer, V.R.; Brown, P. O. Science 1997, 278, 680.

[3] Van Hal, N.L.; Vorst, O.; Van Houwelingen, A.M.; Kok, E.J.; Peijnenburg, A.; Aharoni, A.; Van Tunen, A. J.; Keijer, J. J. Biotechnol. 2000, 78, 271. 
[4] DeRisi, J.; Penland, L.; Brown, P. O.; Bittner, M. L.; Meltzer, P. S.; Ray, M.; Chen, Y.; Su, Y.A.;Trent, J. M. Nat. Genet. 1996, 14, 457.

[5] Heller, R.A.; Schena, M.; Chai, A.; Shalon, D.; Bedilion, T.; Gilmore, J.; Woolley, D.E.; Davis, R.W. Proc. Natl. Acad. Sci. 1997, 94, 2150.

[6] Dufva, M. Biomol. Eng., 2005, 22173.

[7] Pirrung, M.C. Angew. Chem., Int. Ed. 2002, 41, 1276.

[8] Pirrung, M.C. Chem. Rev. 1997, 97, 473.

[9] Fodor, S.P.; Read, J.L.; Pirrung, M.C.; Stryer, L.; Lu, A. T.; Solas, D. Science 1991, 251, 767.

[10] Pease, A.C.; Solas, D.; Sullivan, E.J.; Cronin, M. T.; Holmes, C.P.; Fodor, S.P. Proc. Natl, Acad. Sci. 1994, 91, 5022.

[11] McGall, G.; Fidanza, J.A. in: Methods in molecular biology, Humana Press (Totowa, NJ) 2001, p. 71.

[12] Rose, D. in: Microarray Biochip Technology, Schena M., Ed., (Eaton, Natick) 2000, p. 19.

[13] Martinsky, T.; Haje, P. in: Microarray Biochip Technology, Schena M., Ed., (Eaton, Natick) 2000, p. 201.

[14] Mace, M.L.; Montagu, J.; Rose, S.D.; McGuinness, G. in: Microarray Biochip Technology, Schena M., Ed., (Eaton, Natick) 2000, p. 39.

[15] Okamoto, T.; Suzuki, T.; Yamamoto, N. Nat. Biotechnol. 2000, 18, 438.

[16] Cooley, P.; Hinson, D.; Trost, H. J.; Antohe, B.; Wallace, D. in: Methods in molecular biology, Humana Press (Totowa, NJ,) 2001, p. 117.

[17] Gong, P.; Grainger, D.W. Surf. Sci., 2004, 570, 67.

[18] Benters, R.; Niemeyer, C.M.; Drutschmann, D.; Blohm, D.; Wohrle, D. Nucleic Acids Res. 2002, 30, 10.

[19] Wicks, D.A.; Wicks, Z.W. Progr. Org. Coat. 1999, 36, 148.

[20] Wicks, D.A.; Wicks, Z.W. Progr. Org. Coat. 2001, 43, 131.

[21] Wicks, D.A.; Wicks, Z.W. Progr. Org. Coat. 2001, 41, 1.

[22] Vigano, M.; Suriano, R.; Levi, M.; Turri, S.; Damin, F.; Chiari, M. Surf. Sci. 2007, 601, 1365.

[23] Joos, B.; Kuster, H.; Cone R. Anal. Biochem., 1997, 24, 96.

[24] Oh, S.J.; Cho, S.J.; Kim, C.O.; Park, J.W. Langmuir, 2002, 18, 1764.

[25] Beier, M.; Hoheisel, J.D. Nucleic Acid Res. 1999, 27, 1970.

[26] Le Berre, V.; Trevisol, E.; Dagkessamanskaia, A.; Sokol, S.; Caminade, A.M.; Majoral, J.P.; Meunier, B.; Francois, J. Nucleic Acid Res. 2003, 31 e88.

[27] Pirri, G.; Damin, F.; Chiari, M.; Bontempi, E.; Depero, L.E. Anal. Biochem. 2004, $76,1352$.

[28] Hong, B.J.; Oh, S.J.; Youn,T.O.; Kwon, S.H.; Park, J.W. Langmuir 2005, 21 4257.

[29] Wicks, Z.W.; Jones, F.N.; Pappas, S.P. in: Organic Coatings, Science and Technology: Second Edition, Wiley (NY) 1999.

[30] Sompuram, S.R.; Vani, K.; Wei, L.; Ramanathan, H.; Olken, S.; Bogen, S.A. Anal. Biochem. 2004, 32655.

[31] Extrand, C.W. J. Colloid Interf. Sci., 1998, 207, 11

[32] Ming, C.C. in: Polymer surface modification and characterization, Hanser Garden Publications (Munich) 1994, p. 39. 